\title{
Aplicação da análise de regressão linear na estimativa do coeficiente de dilatação térmica dos ésteres palmitoleato de metila e oleato de metila
}

César Augusto Canciam, Mestre em Engenharia Química, professor lotado no Departamento Acadêmico de Engenharia Química da Universidade Tecnológica Federal do Paraná - Câmpus Ponta Grossa, canciam@utfpr.edu.br

Recebido em: 24/05/2013 - Aprovado em: 30/07/2013 - Disponibilizado em: 15/08/2013

\section{RESUMO:}

O coeficiente de dilatação térmica é uma propriedade termodinâmica que fornece uma medida da variação da massa específica em resposta à variação da temperatura, mantendo a pressão constante. Com base no coeficiente de dilatação térmica, é possível avaliar o impacto da dilatação térmica sobre a medição volumétrica. O objetivo deste trabalho foi estimar o coeficiente de dilatação térmica dos ésteres palmitoleato de metila e oleato de metila. Para tanto, foi realizada uma análise de regressão linear de dados estimados da massa específica de cada éster em função da temperatura. Os valores encontrados para o coeficiente de dilatação térmica foram de $8,799 \times 10^{-4}$ (palmitoleato de metila) e $8,801 \times 10^{-4}$ $\mathrm{K}^{-1}$ (oleato de metila), em um intervalo de temperatura de 293,15 a 383,15 K e pressão de 1 atm. Em todos os casos estudados, os coeficientes de correlação foram próximos da unidade, classificando a correlação linear como muito forte. PALAVRAS-CHAVE: Ésteres metílicos. Dilatação. Estimativa. Regressão linear.

\section{Application of linear regression analysis to estimate the thermal expansion coefficient of esters methyl palmitoleate and methyl oleate}

\begin{abstract}
:
The thermal expansion coefficient is a thermodynamic property that provides a measure of the specific weight variation in response to temperature variation, keeping the pressure constant. On the basis of the thermal expansion coefficient is possible to evaluate the impact of thermal dilatation on the volumetric measurement. The objective of this work was estimate the thermal expansion coefficient of esters methyl palmitoleate and methyl oleate. For this purpose, it was performed a linear regression analysis of estimated data of specific weight of each ester in a function of temperature. The values found for the thermal expansion coefficient were $8.799 \times 10^{-4}$ (methyl palmitoleate) and $8.801 \times 10^{-4} \mathrm{~K}^{-1}$ (methyl oleate), in the temperature range of 293.15 to $383.15 \mathrm{~K}$ and pressure equal to $1 \mathrm{~atm}$. In all cases studied, the correlation coefficients were near to unit, classifying as a very strong linear correlation.
\end{abstract}

KEYWORDS: Methyl esters. Dilatation. Estimate. Linear regression.

\section{INTRODUÇÃO}

O uso de recursos renováveis, como óleos vegetais e gorduras, tem atraído diversas áreas de estudo, devido aos custos baixos, por serem materiais biodegradáveis e ao grande potencial para substituição de derivados petroquímicos (NICOLAU et al., 2007).

De acordo com a Resolução $n^{\circ} 42$ de 24 de novembro de 2004 da Agência Nacional do Petróleo (ANP), biodiesel é definido como 
sendo o combustível composto de alquilésteres de ácidos graxos de cadeia longa, derivados de óleos vegetais ou de gorduras animais (ENCARNAÇÃO, 2007).

Segundo Albuquerque (2010), o biodiesel metílico é um combustível constituído por uma mistura de ésteres metílicos de ácidos graxos (geralmente FAMEs - "Fatty Acid Methyl Esters"), obtidos pela reação de transesterificação de óleos vegetais ou gorduras animais.

A reação de transesterificação corresponde a uma reação orgânica, na qual um éster é transformado em outro através da troca de grupos alcóxidos. Assim, na transesterificação de óleos vegetais e gorduras, um triglicerídeo reage com um álcool, na presença de catalisador, produzindo uma mistura de ésteres monoalquílicos de ácidos graxos e glicerol (GARCIA, 2006).

Os ésteres graxos produzidos através de uma reação de transesterificação são insumos básicos para uma ampla variedade de derivados oleoquímicos com alto valor agregado. No caso dos ésteres monoalquílicos, esses podem ser utilizados na produção de polímeros, lubrificantes, produtos de higiene pessoal, papel e alimentos, comenta a mesma autora.

Cada material reage diferentemente a uma variação de temperatura. Alguns materiais apresentam uma grande variação nas suas dimensões com o aumento de temperatura. Enquanto que outros praticamente não mudam suas dimensões (CABRAL e LAGO, 2002).

O coeficiente de dilatação térmica está relacionado com a resposta dos materiais à aplicação de calor (CALLISTER, 2008).

A dilatação térmica pode ser interpretada como resultado do aumento das distâncias intermoleculares devido ao aumento da energia cinética das moléculas. Assim, quanto maior a dilatação térmica, maior deve ser a variação da energia cinética das moléculas e, portanto, maior a variação da temperatura. Além disso, deve-se considerar que materiais diferentes podem apresentar maior ou menor variação nos seus volumes, uma vez que a interação entre suas moléculas é diferente (CABRAL e LAGO, 2002).

Neste sentido, Santos e Vieira (2010) comentam que o coeficiente de dilatação térmica está relacionado com a energia de ligação química entre as partículas, de maneira que, materiais em que as ligações químicas são fortes, o coeficiente de dilatação térmica é baixo. Isto porque a dilatação térmica está associada com a variação assimétrica da energia de ligação com a distância entre as partículas. Ou seja, durante o aquecimento, aumentam a frequência e a amplitude de vibração das partículas e como as forças repulsivas são sempre maiores que as forças atrativas, a distância média entre as partículas também aumenta.

Os ésteres são compostos orgânicos derivados dos ácidos carboxílicos pela substituição da hidroxila por um grupo alquila 
ou arila. Via de regra, são substâncias presentes no estado líquido e menos densas que a água, devido à ausência de ligações de hidrogênio (SKORONSKI, 2006).

Os ésteres de menor massa molar são líquidos e conforme aumenta a massa molar passam de líquidos oleosos e viscosos a sólidos (SOLOMONS e FRYHLE, 2009).

As moléculas dos ésteres apresentam certa polaridade devido à presença de dois átomos de oxigênio e ao ângulo formado entre as ligações dos átomos no grupo funcional. Essa polaridade é mais acentuada em ésteres de cadeia carbônica pequena, em que predominam as interações intermoleculares do tipo dipolo permanente-dipolo permanente. À medida que a cadeia carbônica aumenta, a polaridade vai se tornando menor e passam a existir interações intermoleculares do tipo forças de van der Waals (SOLOMONS e FRYHLE, 2009).

De acordo com Teixeira, Coutinho e Gomes (2001), as forças de van der Waals são originadas a partir da rápida flutuação da densidade eletrônica de cada átomo que induz a formação de um momento elétrico entre os átomos vizinhos, fazendo com que esses se atraiam.

O conhecimento do coeficiente de dilatação térmica de uma substância permite (JERÔNIMO， 2012； CANCIAM， 2012a; SANTOS e VIEIRA, 2010; YOUNG e FREEDMAN, 2008):
- Avaliar os impactos no sistema de medição volumétrico decorrentes da variação de temperatura;

- Projetar equipamentos e acessórios considerando a dilatação provocada pelas grandes variações de temperatura;

- Auxiliar na estimativa de outras propriedades, dentre elas, a tensão volumétrica e a entalpia de vaporização;

- Estudar a convecção livre que influencia na transferência de calor em tubulações.

O objetivo deste trabalho foi estimar o coeficiente de dilatação térmica dos ésteres metílicos de ácidos graxos insaturados: palmitoleato de metila $\left(\mathrm{C}_{17} \mathrm{H}_{32} \mathrm{O}_{2}\right)$ e oleato de metila $\left(\mathrm{C}_{19} \mathrm{H}_{36} \mathrm{O}_{2}\right)$. Para tanto, foi utilizado o modelo empírico da massa específica desses ésteres proposto por Verduzco (2013), em um intervalo de temperatura de 293,15 a 383,15 $\mathrm{K}$ e pressão de $1 \mathrm{~atm}$.

\section{MATERIAIS E MÉTODOS}

Para a obtenção do coeficiente de dilatação térmica $(\gamma)$ dos ésteres metílicos estudados foi considerada a metodologia proposta por Canciam (2012a).

Essa metodologia considera que a análise de regressão linear de dados de $\ln \left(\frac{\rho_{0}}{\rho}\right) \quad$ versus $\quad\left(T-T_{0}\right) \quad$ fornece um coeficiente angular que é numericamente 
igual ao coeficiente de dilatação térmica, com base na Equação 1.

$$
\ln \left(\frac{\rho_{0}}{\rho}\right)=\gamma \cdot\left(T-T_{0}\right)
$$

Em que $\left(T-T_{0}\right)$ refere-se à diferença

entre as temperaturas final e inicial e $\left(\frac{\rho_{0}}{\rho}\right)$, à razão entre a massa específica na temperatura inicial e a massa específica na temperatura final.

As massas específicas dos ésteres metílicos estudados foram estimadas através da Equação 2, obtida do trabalho de Verduzco (2013).

$$
\rho=1,069+\left(\frac{3,575}{M}\right)+(0,0113 \cdot N)-\left(7,41 \cdot 10^{-4} \cdot T\right)
$$

Em que $M$ corresponde à massa molar do éster metílico (em g.mol $\left.{ }^{-1}\right), N$, ao número de insaturações (ligações duplas) presentes na molécula do éster e $T$, à temperatura (em K).

A unidade da massa específica $(\rho)$ na Equação 2 corresponde a g.cm ${ }^{-3}$.

A Tabela 1 relaciona a massa molar e o número de insaturações dos ésteres metílicos estudados.

Com base na Equação 2 e nos dados indicados na Tabela 1 , foram estimados os valores da massa específica de cada um dos ésteres metílicos em função da temperatura.

As temperaturas consideradas foram de $293,15 \mathrm{~K}, 303,15 \mathrm{~K}, 313,15 \mathrm{~K}, 323,15 \mathrm{~K}$, $333,15 \mathrm{~K}, 343,15 \mathrm{~K}, 353,15 \mathrm{~K}, 363,15 \mathrm{~K}$, $373,15 \mathrm{~K}$ e $383,15 \mathrm{~K}$.

Tabela 1 - Dados referentes aos ésteres metílicos estudados

\begin{tabular}{ccc}
\hline Éster metílico & $M\left(\mathrm{~g} . \mathrm{mol}^{-1}\right)$ & $N$ \\
\hline Palmitoleato de metila & 268,4348 & 1 \\
Oleato de metila & 296,4879 & 1 \\
\hline
\end{tabular}

Fonte: VERDUZCO (2013).

Adotou-se como sistema de unidades, o Sistema Internacional (SI). Assim, os valores encontrados para a massa específica de cada éster, através da Equação 2, foram convertidos para kg. $\mathrm{m}^{-3}$.

Para a obtenção do coeficiente de dilatação térmica foi considerada como temperatura inicial $\left(T_{0}\right)$ a temperatura de $293,15 \mathrm{~K}$ e a massa específica inicial $\left(\rho_{0}\right)$, à massa específica correspondente a temperatura inicial de cada éster metílico estudado.

\section{RESULTADOS E DISCUSSÃO}

A Tabela 2 indica os valores estimados para as massas específicas dos ésteres palmitoleato de metila e oleato de metila em função da temperatura, a partir da Equação 2 e aos dados indicados na Tabela 1.

Veny e coautores (2009) relatam que a massa específica de ésteres metílicos de 
ácidos graxos depende da massa molar, do conteúdo de ácidos graxos livres, do conteúdo de água e da temperatura.

Tabela 2 - Valores estimados da massa específica em função da temperatura

\begin{tabular}{ccc}
\hline $\begin{array}{c}\text { Temperatura } \\
(\mathrm{K})\end{array}$ & $\begin{array}{c}\text { Massa específica } \\
\left(\mathrm{kg} \cdot \mathrm{m}^{-3}\right)\end{array}$ & $\begin{array}{c}\text { Massa específica } \\
\left(\mathrm{kg} \cdot \mathrm{m}^{-3}\right)\end{array}$ \\
\cline { 2 - 3 } & $\begin{array}{c}\text { Palmitoleato de } \\
\text { metila }\end{array}$ & Oleato de metila \\
\hline 393,15 & 876,4 & 875,1 \\
303,15 & 869,0 & 867,7 \\
313,15 & 861,6 & 860,3 \\
323,15 & 854,2 & 852,9 \\
333,15 & 846,8 & 845,5 \\
343,15 & 839,3 & 838,1 \\
353,15 & 831,9 & 830,7 \\
363,15 & 824,5 & 823,3 \\
373,15 & 817,1 & 815,9 \\
383,15 & 809,7 & 808,4 \\
\hline
\end{tabular}

Fonte: Autor.

Pode-se observar na Tabela 2, que em todas as temperaturas, o éster oleato de metila apresentou a menor massa específica em relação ao éster palmitoleato de metila.

Pratas e coautores (2010), estudando a massa específica e a viscosidade de ésteres metílicos e etílicos de ácidos graxos, constataram que a massa específica desses dois tipos de ésteres diminui com o aumento do comprimento da cadeia alquílica.

Dessa forma, os resultados obtidos para a massa específica dos ésteres metílicos estudados corroboram com o trabalho de Pratas e coautores (2010).

A Figura 1 ilustra o gráfico de $\ln \left(\frac{\rho_{0}}{\rho}\right) \quad$ versus $\quad\left(T-T_{0}\right) \quad$ para $\quad$ o $\quad$ éster palmitoleato de metila. Já a Figura 2 ilustra o mesmo gráfico para o éster oleato de metila.
A Tabela 3 relaciona os valores encontrados para o coeficiente de dilatação térmica $(\gamma)$ de cada um dos ésteres metílicos estudados, bem como o coeficiente de correlação $\left(R^{2}\right)$.

Figura 1: Gráfico $\ln \left(\frac{\rho_{0}}{\rho}\right)$ versus $\left(T-T_{0}\right)$ para o éster palmitoleato de metila

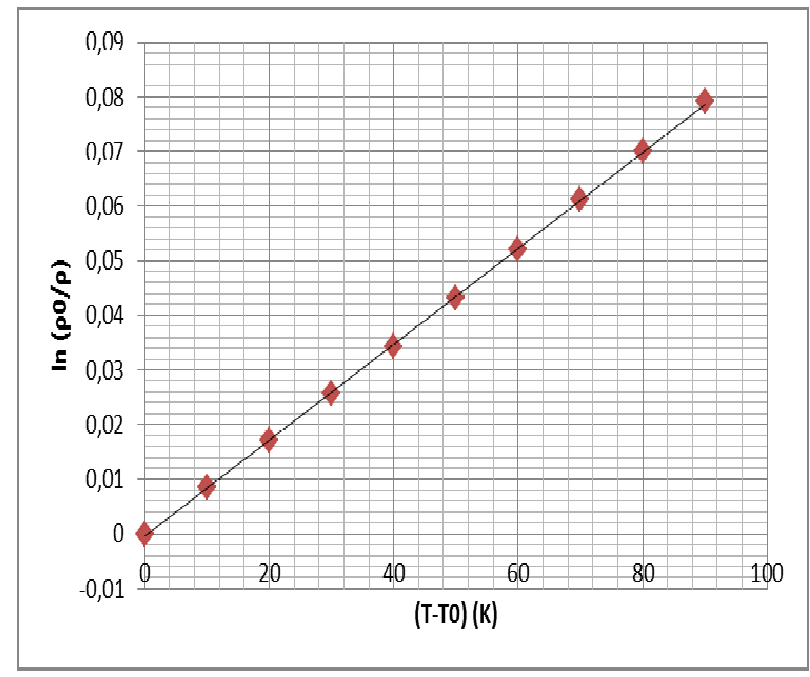

Figura 2: Gráfico $\ln \left(\frac{\rho_{0}}{\rho}\right)$ versus $\left(T-T_{0}\right)$ para o éster oleato de metila

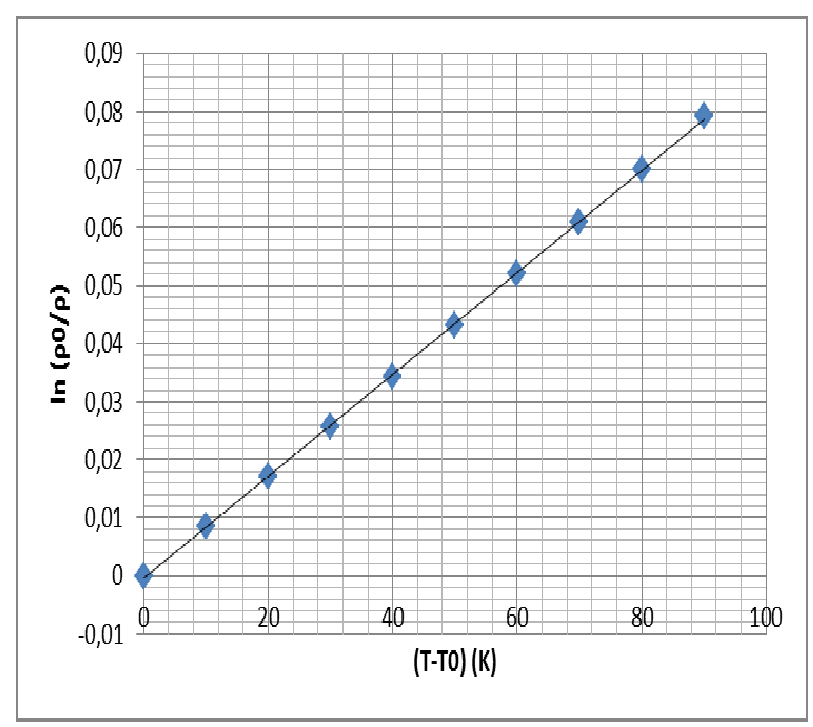


Tabela 3 - Valores obtidos para os coeficientes de dilatação térmica e de correlação

\begin{tabular}{ccc}
\hline Éster metílico & $\gamma\left(\mathrm{K}^{-1}\right)$ & $R^{2}$ \\
\hline Palmitoleato de metila & $8,799.10^{-4}$ & 0,99 \\
Oleato de metila & $8,801.10^{-4}$ & 0,99 \\
\hline Fonte: Autor. & &
\end{tabular}

Pinheiros e coautores (2009) comentam que o coeficiente de correlação $\left(R^{2}\right)$ mede a interdependência linear entre as variáveis e avalia a qualidade do ajuste, ou seja, quanto mais próximo o coeficiente de correlação for da unidade, melhor o ajuste da reta em relação aos pontos da dispersão.

Pode-se observar na Tabela 3 que o coeficiente de correlação está próximo da unidade.

$$
\text { Lira (2004) e Carvalho (2005) }
$$
comentam que a correlação linear é classificada como muito forte quando os valores do coeficiente de correlação encontram-se localizados entre 0,90 e 1,0 .

Dessa forma, a correlação linear é classificada como muito forte.

De acordo com Solomons e Fryhle (2009), nos ésteres, à medida que a cadeia carbônica aumenta, a polaridade vai se tornando menor, e consequentemente, diminuindo as forças intermoleculares. Como o coeficiente de expansão térmica é inversamente proporcional às forças intermoleculares estabelecidas (SANTOS e VIEIRA, 2010). É de se esperar que o éster oleato de metila apresente o maior coeficiente de dilatação térmica.
Assim, os resultados obtidos para os coeficientes de dilatação térmica dos ésteres metílicos estudados corroboram com as discussões realizadas por Solomons e Fryhle (2009) e Santos e Vieira (2010).

A Tabela 4 relaciona a razão $(\theta)$ entre o coeficiente de dilatação térmica de cada éster metílico estudado e o coeficiente de dilatação térmica da água. $\mathrm{O}$ valor do coeficiente de dilatação térmica da água considerado é de $2,07.10^{-4} \mathrm{~K}^{-1}$ e foi adaptado do trabalho de Cabral e Lago (2002).

Tabela 4 - Razão entre os coeficientes de dilatação térmica dos ésteres metílicos estudados e a água

\begin{tabular}{cc}
\hline Éster metílico & $\theta$ (adimensional) \\
\hline Palmitoleato de metila & 4,251 \\
Oleato de metila & 4,252 \\
\hline
\end{tabular}

Fonte: Autor.

A água apresenta interações intermoleculares do tipo ligações de hidrogênio. As ligações de hidrogênio, em comparação com as forças de van der Waals (características nos ésteres de cadeia carbônica grande), são mais fortes (BRUICE, 2006).

Assim, a relação entre essas interações, confere, entre os coeficientes de dilatação térmica, uma razão $\theta$ que é igual a 4,251 (para o éster palmitoleato de metila) e 4,252 (para o éster oleato de metila), conforme indicado na Tabela 4.

A Tabela 5 relaciona a razão $(\theta)$ entre o coeficiente de dilatação térmica de alguns 
ésteres e o coeficiente de dilatação térmica da água.

Tabela 5 - Razão entre os coeficientes de dilatação térmica de alguns ésteres e a água

\begin{tabular}{rcc}
\hline Éster & $\theta$ & Referência \\
\hline Isovalerato de etila & 3,79 & Canciam (2012b) \\
Hexanoato de etila & 4,06 & Canciam (2012b) \\
Propionato de etila & 4,72 & Canciam (2012b) \\
\hline Fonte: Autor. & &
\end{tabular}

Comparando as Tabelas 4 e 5, pode-se observar que a razão $\theta$ para os ésteres metílicos estudados são maiores que a razão $\theta$ correspondente ao éster hexanoato de etila e menores que a razão correspondente ao éster propionato de etila.

Maiores valores para a razão $\theta$ indicam que o coeficiente de dilatação térmica da substância é maior em relação ao coeficiente de dilatação térmica da água e, portanto, nessa substância as interações intermoleculares são fracas.

Assim, pode-se intuir que as interações intermoleculares no éster propionato de etila são comparativamente mais fracas em relação aos ésteres metílicos estudados.

Por sua vez, as interações intermoleculares nos ésteres metílicos estudados são mais fracas em relação ao éster hexanoato de etila.

De acordo com Bruice (2006), a massa específica de um líquido reflete o grau de empacotamento de suas moléculas, o que é decorrência da intensidade das interações intermoleculares. $\mathrm{Ou}$ seja, interações intermoleculares mais intensas tende a se relacionar com massas específicas maiores, uma vez que o volume e a massa específica são inversamente proporcionais. Assim, quanto mais forte a interação intermolecular, mais empacotadas estão as moléculas, pois o volume será menor e a massa específica maior.

Comparando as Tabelas 2 e 3, verifica-se que o palmitoleato de metila apresenta o menor coeficiente de dilatação térmica. Em contrapartida, em todas as temperaturas consideradas, as massas específicas foram maiores em comparação ao oleato de metila.

Dessa forma, as moléculas do palmitoleato de metila devem estar mais empacotadas em comparação às moléculas do oleato de metila, devido às interações intermoleculares mais fortes.

O coeficiente de dilatação térmica mede a variação relativa do volume devido à alteração da temperatura, mantendo-se a pressão constante. Assim, se o coeficiente de dilatação térmica de um material equivale a $1,0.10^{-2} \mathrm{~K}^{-1}$ significa que o acréscimo de 1 grau tem como resultado o aumento do volume em 1\% (NETZ; ORTEGA, 2008).

Seguindo a mesma linha de raciocínio, para cada 1 grau de acréscimo de temperatura, o aumento do volume do éster palmitoleato de metila é de $0,08799 \%$. Para o éster oleato de 
metila, esse valor equivale a $0,08801 \%$. A diferença entre os percentuais é de $0,00002 \%$.

Esses valores podem parecer pequenos, mas se comparados à água $(0,0207 \%)$, o aumento do volume do éster palmitoleato de metila (por exemplo) é da ordem de 4,251 vezes mais que o aumento do volume de água.

Canciam (2012c) verificou que a ordem de aumento de volume para o biodiesel metílico filtrado de gordura vegetal hidrogenada residual correspondeu a 8,67 litros. Enquanto que a ordem de volume para o biodiesel metílico de coco foi de 9,07 litros. Em ambos os casos, considerou uma variação de $10^{\circ} \mathrm{C}$ e um volume de 1000 litros de cada biodiesel específico.

Com o mesmo raciocínio, para os ésteres metílicos estudados, a ordem de aumento no volume desses ésteres é de 8,799 litros (para o palmitoleato de metila) e 8,801 litros (para o oleato de metila), considerando uma variação de $10 \mathrm{~K}$ para cada 1000 litros do éster específico.

\section{CONCLUSÃO}

O objetivo deste trabalho foi estimar o coeficiente de dilatação térmica dos ésteres metílicos insaturados: palmitoleato de metila $\left(\mathrm{C}_{17} \mathrm{H}_{32} \mathrm{O}_{2}\right)$ e oleato de metila $\left(\mathrm{C}_{19} \mathrm{H}_{36} \mathrm{O}_{2}\right)$.

Os valores encontrados para o coeficiente de dilatação térmica foi de $8,799.10^{-4} \mathrm{~K}^{-1}$ (para o palmitoleato de metila) e $8,801.10^{-4} \mathrm{~K}^{-1}$ (para o oleato de metila), em um intervalo de temperatura de 293,15 a 383,15 K e pressão de 1 atm.

Para todos os ésteres metílicos estudados, a correlação linear foi classificada como muito forte.

Os resultados obtidos sugerem que na medida em que se aumenta a cadeia carbônica do éster metílico insaturado, maior é o coeficiente de dilatação térmica.

A ordem de aumento no volume dos ésteres metílicos estudados foi de 8,799 litros (palmitoleato de metila) e 8,801 litros (oleato de metila), considerando uma variação de 10 K para cada 1000 litros do éster específico.

Esses valores são próximos aos encontrados para os biodieseis metílicos de coco e de gordura vegetal hidrogenada residual.

\section{REFERÊNCIAS}

ALBUQUERQUE, A. R. Autoxidação de ésteres metílicos de ácido graxos: estudo teórico-experimental. Dissertação de Mestrado do Programa de Mestrado em Química da Universidade Federal da Paraíba, 2010. 120p.

BRUICE, P. Y. Química Orgânica - volume 2. Pearson Education do Brasil, São Paulo, 2006. 641p.

CABRAL, F.; LAGO, A. Física 2. Harbra, São Paulo, 2002. 516p. 
CALliSTER, W. D. Ciência e Engenharia de Materiais: uma introdução. LTC, Rio de Janeiro, 2008. 590p.

CANCIAM, C. A. Predição do coeficiente de expansão térmica do óleo de girassol através da aplicação da análise de regressão linear. Revista Brasileira de Tecnologia Agroindustrial, v. 6, n. 2, p. 852-863, 2012a.

CANCIAM, C. A. Predição do coeficiente de expansão térmica dos ésteres: propionato de etila, isovalerato de etila e hexanoato de etila. Revista CIATEC - UPF, v. 4, n. 1, p. 11-18, 2012b.

CANCIAM, C. A. Predição dos coeficientes de expansão térmica de biodieseis de diversas origens através da aplicação da regressão linear. Revista e-xacta, v. 5, n. 1, p. 67-82, 2012c.

CARVALHO, M. J. S. Quimiometria e Espectroscopia no Infravermelho Próximo (NIR) e Médio (MIR). Dissertação de Mestrado em Química do Instituto Militar de Engenharia, 2005. 121p.

ENCARNAÇÃO, A. P. G. Geração de biodiesel pelos processos de transesterificação e hidroesterificação, uma avaliação econômica. Dissertação de Mestrado em Tecnologia de Processos Químicos e Bioquímicos da Universidade Federal do Rio de Janeiro, 2007. 144p.
GARCIA, C. M. Transesterificação de óleos vegetais. Dissertação de Mestrado em Química da Universidade Estadual de Campinas, 2006. 136p.

JERÔNIMO, C. E. M. Predição do coeficiente de dilatação térmica de naftas pela curva de destilação ASTM. Revista Virtual de Química, v. 4, n. 4, p. 405-412, 2012.

LIRA, S. A. Análise de correlação: abordagem teórica e de construção dos coeficientes com aplicação. Dissertação de Mestrado em Ciências da Universidade Federal do Paraná, 2004. 196p.

NETZ, P. A.; ORTEGA, G. G. Fundamentos de físico-química: uma abordagem conceitual para as ciências farmacêuticas. Artmed, Porto Alegre, 2008. 299p.

NICOLAU, A.; MARTINI, D. S.;

REIZNAUTT, Q. B.; PEDROTTI, F.;

DALCIN, F. M.; FRANKENBERG, J. G.; SAMIOS, D. Obtenção e caracterização de ésteres e poliésteres a partir de ácidos graxos insaturados. In: Reunião Anual da Sociedade Brasileira de Química, 30, 2007, Águas de Lindóia: Anais... Águas de Lindóia: SBQ, 2007.

PINHEIRO, J. I. D.; CUNHA, S. B.; CARVAJAL, S. R.; GOMES, G. C. 
Estatística básica: a arte de trabalhar com

dados. Elsevier, Rio de Janeiro, 2009. 295 p.

PRATAS, M. J.; FREITAS, S.; OLIVEIRA, M. B.; MONTEIRO, S. C.; LIMA, A. S.; COUTINHO, J. A. P. Densities and Viscosities of Fatty Acid Methyl and Ethyl Esters. Journal of Chemistry \& Engineering Data, v. 55, p. 3983-3990, 2010.

SANTOS, D. Q.; VIEIRA, D. F. Determinação de coeficiente de expansão térmica do biodiesel e seus impactos no sistema de medição volumétrico. Eclética Química, v. 35, n. 4, p. 107-112, 2010.

SKORONSKI, E. Estudo cinético da síntese do octanoato de n-pentila catalisada pela enzima Lipozyme TL IM. Dissertação de Mestrado em Engenharia Química da Universidade Federal de Santa Catarina, 2009. 87p.

SOLOMONS, T. W. G.; FRYHLE, C. B. Química Orgânica - Volume 2. LTC, Rio de Janeiro, 2009. 518p.

TEIXEIRA, V. G.; COUTINHO, F. M. B.; GOMES, A. S. Principais métodos de caracterização da porosidade de resinas à base de divinilbenzeno. Química Nova, v. 26, n. 6, p.608-818, 2001.

VENY, H.; BAROUTIAN, S.; AROUA, M.
SULAIMAN, N. M. N. Density of Jatropha curcas seed oil and its methyl esters: measurement and estimations. International Journal of Thermophysics, v. 30, p. 529-541, 2009.

VERDUZCO, L. F. R. Density and Viscosity of Biodiesel as a function of temperature: empirical models. Renewable and Sustainable Energy Reviews, v. 19, p. 652-665, 2013.

YOUNG, H. D.; FREEDMAN, R. A. Física

III - Termodinâmica e Ondas. Addison

Wesley, São Paulo, 2008. 352p.

K.; HASAN, M.; RAMAN, A. A.; 